\title{
OS DEBATES SOBRE AS PARTICULARIDADES DO TRABALHO DO ASSISTENTE SOCIAL
}

\author{
Alícia Ferreira de Paiva ${ }^{1}$ \\ Ana Bárbara Martiniano Salgado ${ }^{2}$
}

RESUMO: O artigo apresentado traz a discussão sobre as individualidades do trabalho do assistente social, desde sua institucionalização como profissão na década de 30, trazendo elementos fundamentais como trabalho assalariado; autonomia relativa; precarização; entres outros. Ademais, analisa as peculiaridades de produção capitalista e a interdependência entre o mesmo e a profissão. Refere-se a um debate de abordagem teórica realizada através de pesquisas bibliográficas, fundamentadas em diversas obras e autores.

Palavras-chaves: Trabalho. Profissão. Assistente Social.

\section{INTRODUÇÃO}

O presente artigo objetiva analisar as particularidades do trabalho do Assistente Social em sua complexibilidade, desde seus primórdios ao mundo contemporâneo, de forma sucinta. Para a elaboração desta discussão, optamos por produzir uma revisão bibliográfica, utilizando obras de diferentes autores como Sérgio Lessa; José Paulo Netto e em sua maioria, Marilda Iamamoto. Os autores mencionados, nos auxiliarão no embasamento teórico para construção do referido artigo, que mostra em seu percurso a relevância do tema para o assistente social e sua consolidação como trabalhador.

A década de 30, principalmente na era Vargas, foi o momento em que o Serviço Social foi institucionalizado como profissão pelo Governo Federal. Esta decisão teve como finalidade controlar a sociedade, uma vez que, havia grande pressão dos setores emergentes; proletariado, que aumentou com a expansão das indústrias e o Estado receio de uma possível revolução, entendeu que havia à

\footnotetext{
Graduanda em Serviço Social pela Universidade Federal de Viçosa/MG. E-mail: alicia.paiva@ufv.br

${ }^{2}$ Graduanda em Serviço Social pela Universidade Federal de Viçosa/MG. E-mail: ana.b.salgado@ufv.br
} 
necessidade de representantes, que planejassem e implementasse políticas públicas, assim, contendo a ameaça comunista.

Há um grande debate sobre a origem da profissão do assistente social, em que grande parte de estudiosos afirmam que está se derivou da caridade, advinda da religião. Porém, de acordo com Iamamotto (200o), o Serviço Social em sua trajetória histórica perpassou pela filantropia, porém não é evolução da mesma. Como a autora explicita em seu livro, Serviço Social na contemporaneidade:

Por exemplo, aceita-se, como senso comum, que a profissionalização do
Serviço Social surge de uma tecnificação da filantropia. [...] Esta é uma
visão de dentro e por dentro das fronteiras do Serviço Social, como se ele
fosse fruto de uma evolução interna e autônoma das formas de proteção e
de apoio social. Todavia, a constituição e institucionalização do Serviço
Social como profissão na sociedade depende, ao contrário, de uma
progressiva ação do Estado na regulação da vida social [...]"
(IAMAMOTO, 20oo, p.23)

Desde sua institucionalização o Serviço Social foi conservador, porém este posicionamento sofre algumas transformações, a partir do movimento de reconceituação da profissão, mais precisamente, no Congresso da Virada, onde inicia-se a crítica ao conservadorismo da profissão, com o apoio da teoria Marxista e se reconhece como classe trabalhadora, firmando compromisso com a mesma e seus interesses. Ou seja, foi neste processo que a profissão se reconhece com trabalhadores assalariados, pertencentes a esta classe, entendendo que o modo de produção vigente visa a acumulação ${ }^{3}$ de muito por poucos, o que acarreta as diversas expressões da questão social ${ }^{4}$, a qual é objeto de estudo e de trabalho do profissional.

Assim como nos anos 1990 ocorreu a inevitabilidade na criação de um novo currículo para o Serviço Social, o trabalho do assistente social na contemporaneidade ainda apresenta diversificações e particularidades, visto que, o mesmo exerce uma

\footnotetext{
3 "Nem é a acumulação o resultado da abstinência por parte de quem busca satisfazer uma preferência subjetiva pelo CONSUMO futuro às expensas do consumo presente, como afirma a economia neoclássica burguesa que se baseia na teoria da utilidade. Para Marx, um dos aspectos essenciais do CAPITAL é o de que ele tem que ser acumulado, independentemente das preferências subjetivas ou das convicções religiosas dos capitalistas tomados individualmente.” (BOTTOMORE, 1998, p. 13) 4 "Questão social apreendida como o conjunto das expressões das desigualdades da sociedade capitalista madura, que tem uma raiz comum: a produção social é cada vez mais coletiva, o trabalho torna-se mais amplamente social, enquanto a apropriação dos seus frutos mantém-se privada, monopolizada por uma parte da sociedade." (IAMAMOTO, 200o p.27)
} 
profissão que se produz e reproduz no sistema capitalista e seu vasto mercado de trabalho, o qual amplia cada vez mais.

Ademais, na década de 90 com a emergência do neoliberalismo, de forma intensificada, resulta em uma tendência de mercantilização dos direitos sociais, os quais são garantidos através do trabalho do assistente social, fazendo com que o mesmo, busque constantemente novas estratégias para intervir nas expressões da questão social.

O sistema capitalista é sustentado pela relação capital $^{5}$ e trabalho, exploradores e explorados, a qual requer do assistente social, simultaneamente, uma aproximação profissional e uma análise crítica das demandas advindas da exploração sob o proletário. Dessa forma, considera-se a questão social e suas expressões, objetos de intervenção do assistente social.

\section{TRABALHO ASSALARIADO X AUTONOMIA RELATIVA}

O Serviço Social como profissão emergiu-se na sociedade capitalista industrial, momento histórico em que a questão social torna-se mais evidente, com o aumento considerável do proletariado e, ao mesmo tempo, condições degradantes de trabalho e poucos direitos trabalhistas. E como já explicitado neste trabalho, o assistente social é cotado para intervir nas expressões da questão. Essa intervenção na questão social, abandona, em partes, seu lado repressivo, como é descrito por Iamamoto:

Evoca o passado, quando era concebida como caso de polícia, ao invés de ser objeto de uma ação sistemática do Estado no atendimento ás necessidades básicas da classe operária e outros segmentos trabalhadores. $\mathrm{Na}$ atualidade, as propostas imediatas para enfrentar a questão social no país atualizam a articulação assistência focalizada/repressão, com o reforço do braço coercivo do Estado em detrimento da construção do consenso necessário ao regime democrático, o que é motivo de inquietação." (IAMAMOTO, 200I, p. 17)

$\mathrm{O}$ assistente social, assim como qualquer outro inserido na classe trabalhadora, possui sua força de trabalho vendida, resultando no valor de uso ${ }^{6} \mathrm{e}$

\footnotetext{
5 "(...)de um modo geral, portanto, o capital é um bem que pode um fluxo de renda para seu dono." (BOTTOMORE, 1998, p.75)

${ }^{6}$ Para melhor entendimento os termos; valor de uso, valor de troca e mais-valia, recomenda-se a leitura de NETTO e BRAZ (2006).
} 
troca da mesma. Considera-se valor de uso a sua utilidade social, assim como o salário expresso em seu valor de troca e ainda que, o mesmo, não produza mais-valia diretamente, este contribui para a formação da vida social/ideológica do trabalhador.

Simultaneamente, o assistente social é considerado um trabalhador livre, possuindo autonomia em suas atividades, sendo estas, amparadas por estatutos e código de ética. Essa relação de independência profissional é tensionada pelo trabalho assalariado, uma vez que, o assistente social é submetido ao empregador, que geralmente é o Estado, o qual, muitas vezes, restringe a autonomia do profissional. Essa tensão mencionada, nada mais é, que um conflito dos interesses capitalistas e no comprometimento do assistente social com seus usuários, o que resulta em uma fragmentação profissional, pois tem que atender as demandas do capital e da classe trabalhadora, o que é uma situação contraditória.

Esta autonomia modifica conforme o espaço socio-ocupacional em que o assistente social se encontra inserido, visto que, a função/intervenção do mesmo se restringe de acordo com seu empregador e as demandas apontadas pelos subalternos. Em grande parte, o assistente social tende a usar sua autonomia relativa como forma de alterar as condições determinadas pelo empregador para rumos sociais, além de terem como suporte outros profissionais de seguimentos diferente, o próprio movimento de trabalhadores no espaço o qual o assistente social se encontra inserido e as lutas hegemônicas presentes na sociedade. Ademais, é visível que a autonomia do assistente social é vulnerável à pressão da classe trabalhadora em busca de direitos sociais e serviços que possam atender as necessidades da mesma.

Ponderando Iamamoto e Carvalho (1982) aportados pela teoria de Gramsci, o assistente social como intelectual pertencente a classe trabalhadora, é o responsável pela contribuição na construção da consciência, auxiliando no caminho social da mesma. Essa contribuição ideológica sucede com a aplicação dos conhecimentos do assistente social por meio das mediações nas realidades sociais. Contudo, essa contribuição ideológica a ser considerada em todo um contexto social/político, também é tensionada pela autonomia relativa do assistente social, uma vez que, o mesmo é um trabalhador assalariado possuindo submetendo, em grande maioria, ao Estado, como já citado. 
Deste modo, o trabalho do assistente social é resultante de um conjunto de condições externas, causadas pela relação do mercado de trabalho e trabalhador, as quais limitam ou não, o assistente social em suas intervenções, de mesma maneira com que o mesmo, busca se amparar em estratégias éticas-políticas no meio profissional.

\section{A PRECARIZAÇÃO DO TRABALHO DO ASSISTENTE SOCIAL}

A precarização do trabalho é fruto da reestruturação produtiva do capital, também conhecido como capital flexível, relacionada com a implantação do neoliberalismo no sistema econômico, a qual se intensifica pela permanente busca da reprodução do capital na sociedade, como alerta Antunes:

[...] o neoliberalismo e a reestruturação produtiva da era da acumulação flexível, dotadas de forte caráter destrutivo, têm acarretado, entre tantos aspectos nefastos, um monumental desemprego, uma enorme precarização do trabalho e uma degradação crescente, na relação metabólica entre homem e natureza, conduzida pela lógica societal voltada prioritariamente para a produção de mercadorias, que destrói o meio ambiente em escala globalizada. (ANTUNES, 20or, p.35).

O assistente social é afetado com essa precarização em várias vertentes, ao mesmo tempo que ocorre a diminuição em cargos de trabalho, sucede um aumento nas políticas sociais devido as demandas dessa fragilização. Outro fator causado pela precarização do trabalho é a terceirização, a qual ataca diretamente os direitos trabalhistas, visto que, a mesma retira qualquer responsabilidade da empresa sobre o funcionário, transferindo-a para um "terceiro". Além disso, a terceirização leva a uma divisão entre a própria classe trabalhadora, causada pela disputa de melhores salários e cargos.

Ressalta-se que, a inserção da tecnologia no mercado de trabalho como meio de impulsionar os processos de trabalho, afeta também o assistente social em sua forma de assistência ao usuário, uma vez que, se torna mais automatizado o atendimento do mesmo, o que causa distanciamento na relação assistente social e usuário. Essa automatização está presente, também, nos diversos formulários a serem preenchidos, os quais muitas vezes, tornam o trabalho do assistente social algo mecânico, perdendo a essência social do mesmo. 
Ademais, é notável a precarização do trabalho do assistente social juntamente com a descentralização das políticas públicas, ampliando o trabalho do assistente social em munícios. Essa interiorização evidencia não só a precariedade em geral no trabalho do assistente social, mas também algumas particularidades desta descentralização como salários irregulares e baixos; contratos temporários, terceirizados e por regalias, o que resulta em uma diminuição de concursos públicos. Essa amostra de precarização causa grandes impactos negativos na qualidade do serviço oferecido aos usuários desse seguimento e um retrocesso nas ações profissionais com bojo teórico crítico.

\section{TRABALHO PRODUTIVO OU IMPRODUTIVO}

O modo de produção capitalista tem como sua base a acumulação, em que, poucos, os capitalistas, acumulam muito, e muitos, o proletariado, não acumula praticamente nada. E a partir desta necessidade burguesa, começa a se rotular o trabalho como produtivo ou improdutivo, em que serviços, em geral, não são considerados produtivos, pois não geram mais valia diretamente, melhor dizendo, não dão possibilidade de que os capitalistas acumulem.

$\mathrm{Ou}$ seja, considera-se trabalho produtivo, àquele que gera riqueza, já o trabalho improdutivo é orientado pela manutenção da ordem social, baseando-se nas classes sociais e não gera riqueza em si.

Para o capital global, só é produtivo o trabalho que aumenta a massa global de mais-valia. Todo trabalho que permita ao capitalista individual apropriarse de uma fração da massa global de mais valia, mas sem nada agregar a essa massa, pode ser "produtivo" [...]” (MANDEL, 1998, p.123)

A polêmica sobre o trabalho do assistente social, abrange também a discussão sobre produtividade. Os principais autores que se contrapõe nesse debate é Marilda Iamamotto, a qual acredita que o Serviço Social é um trabalho, e Sergio Lessa que discorda da mesma. De acordo com Iamamotto, o Serviço Social participa da produção e reprodução da vida social, ainda que não produza mais valia diretamente, ele reproduz a vida social do trabalhador que é a fonte da mais valia, como por exemplo a ideologia da massa dominante e a força de trabalho do proletário, que no 
modelo de produção vigente é o que constitui o modo societário atual. Já Sergio Lessa expõe que:

O Serviço Social não gera um "produto" que subsista para além do final de sua atividade. $\mathrm{O}$ trabalho, ao invés, gera ao seu término meios de produção e de subsistência que, em sendo matéria natural transformada, são "produtos" que não são consumidos no próprio ato de produção." (LESSA, 2010, p. 8o)

Entende-se então que, este autor expõe que somente quando há um produto final, uma função social, reproduzindo a vida social, pode-se considerar trabalho e afirma que o Serviço Social não produz estes quesitos. Explicitando que, o serviço social não gera um produto diretamente, mais sim meios para a produção, não gera algo pronto, não dá resultado imediato e é sim um processo que talvez perdure por muito tempo. Pode-se dizer que, o autor vê o trabalho do assistente social como um gasto que pode não gerar riqueza aos burgueses.

\section{MERCADO DE TRABALHO DO ASSISTENTE SOCIAL}

A profissão de assistente social foi institucionalizada, pela necessidade do

governo controlar a massa subalterna da sociedade, não para garantir apenas seus interesses, mas também e principalmente, para atender as conveniências do capital. Para alcançar seus objetivos, cresceu-se absurdamente o número de políticas públicas e sua abrangência, e o discurso utilizado para conter a população é que eram benefícios e não direitos, deixando em vista com o Estado era quem preza pelo bem estar social.

Para efetivar este controle, o Estado foi o maior empregador de assistentes sociais, para que trabalhassem diretamente com as políticas públicas. Porém, percebese que os municípios são os órgãos do Governo que mais contratam estes profissionais, e isso se dá por causa da descentralização das políticas, maneira que dificulta o acesso aos direitos da população, que têm que enfrentar toda uma burocracia para tentar garantir seus direitos.

Outro aspecto que deve ser apontado, é que mesmo o Estado sendo o maior empregador de assistentes sociais, os espaços sócio ocupacionais destes profissionais são vastos, em que, em cada local, geralmente, para cumprir seu trabalho, o 
profissional deve realizar um processo de trabalho diferente, atendendo as demandas, particularidades e objetivos da instituição que o mesmo está inserido.

Deve-se citar que o Serviço Social deve estar em constante atualização, uma vez que, de acordo com as mudanças que ocorrem na sociedade, om o surgimento e agravamento de "novas" expressões da questão social, o profissional deve estar preparado para atender as novas demandas. Assim como a profissão se transforma os mercados de trabalho dessa profissão também estão em constante mudança.

Sendo assim, apesar da descentralização ter significado abertura do mercado de trabalho, neste mesmo movimento, tem sido exigido dos assistentes sociais adaptação às normas da sociedade flexível, capaz de construir ações fundadas na razão instrumental, restritas ao trânsito do "aqui e agora", em que os fins justificam os meios.” (MORAES E SCHOCAIR, 2018, p. 7)

Logo, segundo o autor, a descentralização das políticas públicas, assim como a maior autônima dos órgãos federativos, e as mudanças societárias, exigem um profissional moderno que possa atuar nos diversos campos profissionais que estão surgindo e nas mais diversas reinvindicações sociais que apresentam-se.

\section{CONSIDERAÇÕES FINAIS}

É evidente que o modo de produção capitalista tem alguns quesitos que permitem sua sobrevivência, e um deste são as expressões da questão social, gerada e agravada da série as desigualdades econômica e sociais, e, principalmente pela relação de exploração sob o trabalhador, que vende sua força de trabalho.

Estas expressões da questão social são objeto de estudo e trabalho do assistente social, o qual deve buscar maneiras pra intervir de modo a beneficiar o trabalhador. É inquestionável que, enquanto essas desigualdade estiverem presentes o trabalho do assistente social será necessário para o Estado.

Outrossim, com o crescimento e fortalecimento do capitalismo, com um governo e empregadores conservadores, o trabalho do assistente social fica comprometido, uma vez que, este como trabalhador assalariado é subordinado, e muitas vezes, não pode usar de sua autonomia para atender as demandas da maneira que ele entende coerente. 
Essas dificuldade de efetivação do trabalho do assistente social, está presente também na inserção do mesmo em determinados espaços de trabalhos, e o processo para realizar seu oficio, pois apesar de, a maioria dos espaços, serem para garantir a proteção social, cada um tem sua demanda, seu modo de gerir e intervir, ou seja, cada um tem seu modo de realizar o trabalho.

Devido a estes e outros motivos, José Paulo Netto (1999), ressalta a importância de uma formação profissional de qualidade, para que formem assistentes sociais capazes de lidar com as novas demandas, que se agravam com a expansão e consolidação do capital, e que entendam a necessidade de estratégias para contornar as dificuldades que se impõe, que não permitem que o profissional possa efetivar seu trabalho, de acordo com o projeto ético-profissional, prezando sempre pelo usuário.

Em poucas palavras, entrou na agenda do Serviço Social a questão de redimensionar o ensino com a vistas á formação de um profissional capaz de responder, com eficácia e competência, ás demandas emergentes na sociedade brasileira- em suma, a construção de um novo perfil profissional." (NETTO, 1999, p. 13).

Essa formação ancorada no projeto ético-político garante ao assistente social suporte técnico e científico para a profissão, sendo este, base fundamental para o entendimento da complexibilidade profissional no mundo contemporâneo, essencial para o distanciamento crítico do capital e aproximação das demandas da classe trabalhadora. Além disso, o projeto ético-político reforça o caráter de equidade e justiça social, buscando reforçar o comprometimento do assistente social na consolidação e defesa dos direitos sociais, políticos e civis, bem como o acesso a serviços prestados a classe trabalhadora, sendo assim, um constante processo. Ressalta-se a importância da construção coletiva do projeto, como vemos em NETTO:

[...] o projeto se declara radicalmente democrático- considerada a democratização como socialização da participação política e socialização da riqueza socialmente produzida." (NETTO, 1999, p. 16)

Diante disso, ainda que o projeto sustente as bases fundamentais da profissão, o mesmo incorpora-se de características flexíveis, que aderem as novas demandas profissionais. 
Ademais, o projeto ético-político da profissão representa uma afronta ao neoliberalismo por se opor a privatização e sucateamento dos serviços/direitos sociais; efetivação da política de economia voltada ao capital entre outros. A consolidação do mesmo, é de não decorre apenas dos profissionais, mas também dos movimentos democráticos que buscam, assim como o projeto, o combate ao neoliberalismo. Esse combate é realizado pela massa de profissionais, através de um comprometimento ético, político, ideológico e social com a massa da classe trabalhadora.

Por conseguinte, vale explicitar sobre como o trabalho do assistente social não é considerado como de grande importância, e um dos vários motivos para essa qualificação, é por muitos entenderem que o mesmo não é produtivo, não gera riqueza, algo que é tão necessário para o capitalismo. E essa desqualificação fia evidente, ao analisarmos a precarização do trabalho, em que o assistente social tem que se submeter a questões e condições de insalubridade e falta de materiais e meios necessários para realização do seu trabalho.

\section{REFERÊNCIAS}

ANTUNES, Ricardo. Trabalho e precarização numa ordem neoliberal. In: GENTILI, P.; FRIGOTTO, G. (Orgs). A cidadania negada: Políticas de exclusão na educação e no trabalho. São Paulo: Cortez, 200I, p. 35-48.

BOTTOMORE, Tom (Org.). Dicionário do pensamento marxista. Rio de Janeiro: Jorge Zahar, 1988.

. CEFESS. Sobre a profissão de Assistente Social. Brasília, jun. 2015.

_. Código de Ética Profissional do Assistente Social. Brasília: CEFESS,ig93.

IAMAMOTO. Marilda. Os Espaços Sócio-ocupacionais do Assistente Social. CFESS, ABEPSS. Serviço Social: direitos sociais e competências profissionais. CEAD/UnB. Brasília, 2009.

IAMAMOTO, Marilda. A questão social no capitalismo. In:Temporalis, Ano 2, n. 3, p.9-32, (jan./jul. 200I), Brasília: ABEPSS, Grafline, 200I.

IAMAMOTO, Marilda. O Serviço Social na contemporaneidade: trabalho e formação profissional. 3. ed. São Paulo: Cortez, 2000. 
IAMAMOTO, M. V.; CARVALHO, R. Relações sociais e serviço social no Brasil: esboço de uma interpretação histórico-metodológica. 19. ed. São Paulo: Cortez, 2006.

LESSA, Sérgio. Serviço Social e trabalho: Porque o serviço social não é trabalho. 2.ed. São Paulo: Instituto Lukács, 2012.

MANDEL, E. "El capital". Cien años de controversias en torno a la obra de Karl Marx. México: Siglo XXI, 1998.

MORAES, C. A. de S.; SCHOCAIR, G. M. M. Trabalho, mercado de trabalho e autonomia relativa do Assistente Social: elementos para análise. Universidade Federal Fluminense, Curso de Serviço Social, Campos dos Goytacazes, 2018.

NETTO, José Paulo. A Construção do Projeto Ético-político do Serviço Social Frente à Crise Contemporânea. In: Crise Contemporânea, Questão Social e Serviço Social. Programa de Capacitação Continuada para Assistentes Sociais. Módulo or. Brasília. CFESS/ABEPSS/DSS e CEAD-UnB, 1999.

NETTO, J.P; BRAZ, M. Economia política: uma introdução a crítica. ı.ed. São Paulo: Cortez, 2006. 